\title{
CLEVER maternity care: A before-and-after study of women's experience of childbirth in Tshwane, South Africa
}

\begin{tabular}{|c|c|}
\hline \multicolumn{2}{|c|}{$\begin{array}{l}\text { Authors: } \\
\text { Sarie J. Oosthuizen }{ }^{1,2,3} \\
\text { Anne-Marie Bergh } \\
\text { Jackie Grimbeek } \\
\text { Robert C. Pattinson }\end{array}$} \\
\hline $\begin{array}{l}\text { Affiliations: } \\
{ }^{1} \text { Tshwane Dist } \\
\text { Department o } \\
\text { Medicine, Uni } \\
\text { Pretoria, Preto } \\
\text { South Africa }\end{array}$ & $\begin{array}{l}\text { rict Health and } \\
\text { f Family } \\
\text { versity of } \\
\text { ria, }\end{array}$ \\
\hline $\begin{array}{l}{ }^{2} \text { Research Cen } \\
\text { Maternal, Feta } \\
\text { and Child Heal } \\
\text { Strategies, Fac } \\
\text { Sciences, Univ } \\
\text { Pretoria, Preto } \\
\text { South Africa }\end{array}$ & $\begin{array}{l}\text { tre for } \\
\text { l, Newborn } \\
\text { Ith Care } \\
\text { ulty of Health } \\
\text { ersity of } \\
\text { ria, }\end{array}$ \\
\hline $\begin{array}{l}{ }^{3} \text { UP/SAMRC U } \\
\text { and Infant Hea } \\
\text { Strategies, Fac } \\
\text { Sciences, Univ } \\
\text { Pretoria, Pretc } \\
\text { South Africa }\end{array}$ & $\begin{array}{l}\text { nit for Maternal } \\
\text { alth Care } \\
\text { ulty of Health } \\
\text { ersity of } \\
\text { ria, }\end{array}$ \\
\hline $\begin{array}{l}\text { Correspondin } \\
\text { Sarie Oosthuiz } \\
\text { sarie.silberbau }\end{array}$ & $\begin{array}{l}\text { g author: } \\
\text { en } \\
\text { er@gmail.com }\end{array}$ \\
\hline $\begin{array}{l}\text { Dates: } \\
\text { Received: } 20 \\
\text { Accepted: } 05 \\
\text { Published: } 15\end{array}$ & $\begin{array}{l}\text { May } 2020 \\
\text { Aug. } 2020 \\
\text { Oct. } 2020\end{array}$ \\
\hline $\begin{array}{l}\text { How to cite th } \\
\text { Oosthuizen SJ, } \\
\text { Grimbeek J, Pa } \\
\text { CLEVER mater } \\
\text { before-and-aft } \\
\text { women's expe } \\
\text { childbirth in Ts } \\
\text { Africa. Afr J Pr } \\
\text { Fam Med. } 202 \\
\text { https://doi.org } \\
\text { phcfm.v12i1.2 }\end{array}$ & $\begin{array}{l}\text { is article: } \\
\text { Bergh A-M, } \\
\text { attinson RC. } \\
\text { nity care: A } \\
\text { ter study of } \\
\text { rience of } \\
\text { swwane, South } \\
\text { m Health Care } \\
0 ; 12(1) \text {, a2560. } \\
\text { /10.4102/ } \\
560\end{array}$ \\
\hline $\begin{array}{l}\text { Copyright: } \\
\text { C 2020. The A } \\
\text { Licensee: AOS } \\
\text { is licensed unc } \\
\text { Creative Comn } \\
\text { Attribution Lic }\end{array}$ & $\begin{array}{l}\text { uthors. } \\
\text { IS. This work } \\
\text { ler the } \\
\text { nons } \\
\text { ense. }\end{array}$ \\
\hline Read online: & \\
\hline 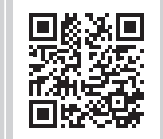 & $\begin{array}{l}\text { Scan this QR } \\
\text { code with your } \\
\text { smart phone or } \\
\text { mobile device } \\
\text { to read online. }\end{array}$ \\
\hline
\end{tabular}

Background: Birthing care matters to women and some women experience mistreatment during childbirth.

Aim: To determine the effect the 'CLEVER Maternity Care' package, a multi-faceted intervention to improve respectful, quality obstetric care.

Setting: Ten midwife-led obstetric units in Tshwane health district, South Africa; five intervention and five control units.

Methods: We conducted an anonymous baseline and end-line survey to measure the change in women's perceptions and experiences of childbirth care after the implementation of the CLEVER package. A convenience sample of women returning for a postnatal follow-up visit was obtained at baseline ( $n=653)$ and after implementation of CLEVER $(n=679)$.

Results: Six survey items were selected as proxies for respectful clinical care. There was no significant change in proportions of responses regarding one question, and with regard to patients receiving attention within $15 \mathrm{~min}$ of arrival, both the intervention and control group units showed a significant increase in positive responses (odds ratios of 8.4 and 6.1, respectively, and $p$ values of 0.0001 and 0.0007). For the remaining four items (asking permission before doing an examination, positive communication, respectful treatment and overall satisfaction), only the intervention group showed a significant positive change (odds ratios ranging from 2.4 to $4.3 ; p \leq 0.0018$ ), with no significant change for the control group (odds ratios between 1.0 and $1.8 ; p \geq 0.0736$ ).

Conclusion: After the implementation of CLEVER Maternity Care, women reported a more positive experience of childbirth. The CLEVER intervention is a potential strategy for addressing respectful, quality obstetric care that warrants further investigation.

Keywords: respectful maternal care; obstetric care; childbirth; quality improvement.

\section{Background}

Health services need to achieve the optimal balance between what health systems can provide in low- and middle-income countries (LMICs) and what women expect during birthing. ${ }^{1,2}$ There is a shift towards respectful, high-quality obstetric care ${ }^{3}$ as well as a renewed focus by the World Health Organization (WHO) on improving maternal and neonatal mortality and morbidity in LMICs. ${ }^{4}$ Birthing care during labour should be a supportive interaction between a woman and the healthcare providers, with attention to respectful care and meeting the sociocultural, emotional and psychological expectations and needs of the woman. ${ }^{5}$ Women's experience of mistreatment during childbirth could contribute to poor health and issues with relationships. ${ }^{6}$

Skilled birth attendants who provide quality care during labour and childbirth and behave respectfully could improve women's satisfaction with childbirth ${ }^{3}$ and also ensure maternal and newborn well-being. ${ }^{7}$ Strategies for improving respectful maternity care need to follow a collaborative improvement approach ${ }^{8,9}$ that incorporates health-systems barriers and systems thinking into pathways of better-sustained care. ${ }^{10,11,12,13}$

Bowser and Hill's landscape analysis of abuse in facility-based childbirth ${ }^{14}$ has been followed by other studies highlighting the mistreatment of birthing women. ${ }^{15,16,17,18}$ Standards for the quality of maternal and newborn care are well documented..$^{19}$ Although health professionals subscribe to 
quality birthing care and accept that a woman is entitled to human rights and deserves respectful treatment, ${ }^{20}$ some fall short in the areas of effective communication and shared decision-making, respectful and dignified care and emotional support during labour. ${ }^{21}$

Many studies in LMICs have highlighted the barriers and the actions required to achieve respectful birthing care..$^{22,23,24,25}$ Quality improvement of care in labour wards should not neglect the professional barriers faced by birth attendants. ${ }^{26}$ Poor functioning of the broader health system, as described in the WHO's building blocks, ${ }^{27}$ can lead to omissions in birthing care that negatively influence the experience for birthing women as well as health professionals.

Studies from South Africa and other LMICs attempted to understand why mistreatment was so prevalent during facility births. ${ }^{15,16,18,28,29}$ A mixed-methods systematic review highlights the following themes of discrimination based on sociodemographic characteristics such as age, ethnicity, race and religion; failure to meet professional standards of care; poor rapport and ineffective communication between women and their care providers; lack of supportive care; and loss of autonomy. ${ }^{30}$ Health-systems constraints include lack of resources, absence of policies and a facility culture aimed at protecting women from mistreatment. ${ }^{30}$

CLEVER Maternity Care ${ }^{31}$ is an intervention package that focuses on achieving high-quality respectful obstetric care in midwife-led obstetric units (MOUs). The acronym CLEVER stands for Clinical care and obstetric triage; Labour ward management to resolve the withholding of care; Eliminate barriers to meet basic human needs; Verify care with monitoring, evaluation and feedback to reach reflective practice; Emergency obstetric simulation training (EOST) to create autopilot sequences during emergencies; and Respectful care to improve birthing women's experiences. ${ }^{31}$

The effects of the pilot implementation of the CLEVER package in the Tshwane health district, South Africa, were measured in terms of perinatal morbidity and mortality as proxies for quality obstetric care and in terms of women's experience of childbirth. Results on the significant improvements in the rates of fresh stillbirths, birth asphyxia and meconium aspiration have been reported elsewhere. ${ }^{31}$ This paper reports the changes in women's experiences of childbirth before and after the implementation of the CLEVER package in the Tshwane district. The research question was as follows: which of the experiences of women delivering in intervention MOUs changed significantly from baseline to end-line when compared with those of women delivering in control MOUs?

\section{Methods}

\section{Study design}

The study reported in this paper was part of the pilot implementation of the broader CLEVER intervention. This study entailed a survey of women's experiences of childbirth and early postnatal care before the start of the intervention, which was repeated after the end of the intervention.

\section{Study setting}

The study was conducted in the Tshwane health district. The district had about 50000 deliveries per annum, of which 18\% were conducted in its MOUs. Midwife-led obstetric units are primary healthcare units that provide 24 -h maternity services and are attached to community health centres. All 10 MOUs in the district were included in the study. There were five non-intervention MOUs. Five MOUs were purposively selected to receive the CLEVER intervention. The latter five were the more underserved facilities located in one geographical area under the same area manager. This minimised intervention spillover to the control MOUs.

\section{Intervention}

The CLEVER Maternity Care package was implemented in three phases. The first phase consisted of a period of creating awareness, soliciting participation from MOUs and carrying out activities aimed at strengthening health systems. Creating awareness included giving feedback of women's experiences of their birthing treatment in MOUs using a baseline survey. ${ }^{32}$ Experience was used as an umbrella term that also encompassed perceptions and satisfaction. The second phase addressed a core group of activities aimed at behavioural change. These consisted of an intensive 3-month engagement with each intervention MOU, followed by a further 6 months of followup support to improve and sustain respectful and safe clinical care practices. The same survey of women's experiences was repeated in the third phase of the intervention as part of the end-line measurement of the effects of working CLEVER. ${ }^{31}$

\section{Study population and sampling}

The study population comprised women who had recently given birth in any of the $10 \mathrm{MOU}$ and returned for a postnatal follow-up visit at primary healthcare facilities from 3 days to 6 weeks after delivery. Contextual constraints prevented sample realisation through random sampling, and a convenience sample of women visiting postnatal care clinics was obtained.

The sampling design was based on historical data of annual deliveries at each MOU in 2015 (delivery range: 390-1502). Although a sample size of 800 was planned for both pre- and post-surveys, 653 questionnaires were returned for the baseline assessment and 679 for the end-line assessment. The sampling design was originally based on $90 \%$ power for a proportional difference; the observed power was $80 \%-85 \%$ based on the realised sample.

\section{Data collection}

The baseline and end-line surveys were conducted for both the intervention and non-intervention MOUs using a selfadministered survey tool. Trained research assistants approached potential participants to complete the questionnaire anonymously. Participants were asked about their experiences regarding communication, labour, clinical 
care and respectful care during confinement. Seven items in the questionnaire elicited demographic data. The remaining 25 items were derived from similar validated surveys that focused on the clinical care received and on client satisfaction. More details on the survey tool have been published in a previous study. ${ }^{32}$

The baseline survey was conducted in the period February 2016 to April 2016. After the intensive 3-month engagement with the intervention MOUs between May 2016 and August 2016, the survey was repeated between October 2016 and December 2016. One unit had to be re-sampled between February 2017 and March 2017 because of compromised data.

\section{Data analysis}

Data were captured on Excel and exported to SAS version 9.4. ${ }^{33}$ Hotdeck imputation ${ }^{34}$ was used to replace missing values in categorical data. Weighting of individual respondents was performed by using the average number of births per month per MOU as the basis, which was obtained from the historical records. The average number of births was then adapted to represent a 2-month period. In the recalculation process, provision was made for the number of births that were recorded over a different number of days per MOU (although, generally speaking, during the same period), separately for the MOUs at baseline and end-line. Finally, weighted percentages were calculated to illustrate the relative representation of each sociodemographic category of the population and each response option. Weighted percentages were also calculated for the responses to individual questionnaire items. Six items covering the main areas of respectful care $\mathrm{e}^{14,19}$ were selected for analysis in greater depth (see Tables 2 and 3 and Figure 1). Three items $(\mathrm{A}, \mathrm{B}, \mathrm{C})$ required a Yes/Unsure/No response, and three items (D, E, F) were measured on a four-point semantic scale. The responses to the last three items were dichotomised between the most positive response versus the rest of the responses reduced to a single category.

The results of the six items were analysed using weighted logistic regressions applied to the survey data stratified by MOU and period (baseline/end-line). The analysis was performed using the Procedure Surveylogistic function of the SAS version 9.4 software. ${ }^{33}$ Odds ratios of end-line relative to baseline and also intervention group relative to control group were calculated for each of the six items by applying logistic regression. The average length in days from baseline to end-line per MOU and the number of previous children delivered by each mother were included as covariates in all models. Further inclusions in these models were the effects of period and treatment groups (control/intervention). The logistic models for comparison of each of the effects, such as age, education, province/ country, length of stay in Tshwane and first language, were refined by the inclusion of the correction factors 'average length in days from baseline to end-line', 'intervention/ control group' and 'baseline/end-line'.

\section{Ethical considerations}

The study was approved by the Research Ethics Committee of the Faculty of Health Sciences, University of Pretoria (Protocol 541/2015), and the Tshwane District Research Committee (Project 62/2015). Written permission for the study was obtained from the facility managers of all participating MOUs. No maternal participants could be identified because the survey was completed anonymously. The cover letter of the questionnaire indicated that giving back the questionnaire to the research team was considered informed consent that the information may be used.

\section{Results}

Table 1 illustrates the sample distribution of the two surveys, based on the sociodemographic characteristics of the baseline and end-line respondents. Although these characteristics cannot be controlled in a before-after study with different respondents in the two surveys, the weighting of the statistical modelling made provision for the population characteristics of historically observed births. Because of the small number of participants, English, Afrikaans and Portuguese first-language speakers were grouped as speakers of languages with a European linguistic structure. The age ranges were similar in the two cohorts.

One observable difference in the end-line survey was the higher percentage of intervention group respondents born in Gauteng (baseline, 47\%; end-line, 60\%) and the lower percentage born in neighbouring countries (baseline, 23\%; end-line, 16\%). For the control units, the proportion of respondents born in Gauteng varied by $1 \%$ between baseline and end-line; however, there was an increase in the number of respondents born in neighbouring countries (baseline, $25 \%$; end-line, $38 \%$ ). In the end-line survey, the control and intervention units saw a decline of $12 \%$ in respondents born in Mpumalanga and 9\% in those born in Limpopo. All the above observations explain some of the differences observed in the length of stay in Tshwane and the first-language mix of respondents between baseline and end-line. Of further note is the higher percentage of respondents with an education level of Grades 8-11 from the control units at the end-line (20\% increase) and the lower percentage of respondents with Grade 12 and above (19\% decrease). This observation could possibly be explained by the larger representation of foreign respondents in the control group in the end-line survey.

Table 2 focuses on the percentage change in the results of the six items relevant to clinical respectful care that were selected for in-depth analysis. Differences were calculated (1) for baseline and end-line within the control and intervention groups and (2) between the control and intervention groups at baseline and end-line. In the baseline survey, the positive responses for Items $\mathrm{A}$ and $\mathrm{C}$ started at more or less the same level for the control and intervention MOUs. With regard to women who were attended to within $15 \mathrm{~min}$ of arrival (Item 
TABLE 1: Sociodemographic characteristics of respondents at baseline $(n=653)$ and end-line $(n=679)$.

\begin{tabular}{|c|c|c|c|c|c|c|c|c|c|}
\hline \multirow[t]{3}{*}{ Indicator } & \multirow[t]{3}{*}{ Category } & \multicolumn{4}{|c|}{ Baseline } & \multicolumn{4}{|c|}{ End-line } \\
\hline & & \multicolumn{2}{|c|}{ Control } & \multicolumn{2}{|c|}{ Intervention } & \multicolumn{2}{|c|}{ Control } & \multicolumn{2}{|c|}{ Intervention } \\
\hline & & $n \dagger$ & $\%$ & $n$ & $\%$ & $n$ & $\%$ & $n$ & $\%$ \\
\hline \multirow[t]{4}{*}{ Age range (years) } & Teenagers: 17-19 & 12 & 4.8 & 38 & 9.6 & 27 & 11.4 & 34 & 6.9 \\
\hline & Young mothers: $20-24$ & 78 & 29.6 & 123 & 33.8 & 80 & 31.6 & 133 & 31.8 \\
\hline & Adult mothers: $25-34$ & 139 & 53.8 & 197 & 47.8 & 131 & 52.5 & 223 & 53.3 \\
\hline & Older mothers: 35 and above & 32 & 11.8 & 34 & 8.9 & 11 & 4.5 & 40 & 7.9 \\
\hline \multirow[t]{4}{*}{ Province/country of birth } & Gauteng Province & 117 & 41.3 & 198 & 46.5 & 113 & 40.2 & 257 & 59.6 \\
\hline & Limpopo and Mpumalanga provinces & 66 & 26.6 & 82 & 23.0 & 38 & 14.3 & 60 & 13.7 \\
\hline & $\begin{array}{l}\text { Other provinces (Eastern Cape, Free } \\
\text { State, KwaZulu-Natal, North West, } \\
\text { Western Cape) }\end{array}$ & 20 & 7.6 & 29 & 7.6 & 19 & 7.9 & 49 & 10.5 \\
\hline & $\begin{array}{l}\text { Neighbouring countries (Zimbabwe, } \\
\text { Mozambique, Malawi and other) }\end{array}$ & 58 & 24.5 & 83 & 22.9 & 79 & 37.6 & 64 & 16.2 \\
\hline \multirow[t]{3}{*}{ Living in Tshwane (years) } & Temporary: 0 to $<1$ & 23 & 9.6 & 34 & 10.2 & 34 & 15.7 & 4 & 1.0 \\
\hline & Short term: $\geq 1$ to $<5$ & 60 & 25.8 & 66 & 18.6 & 62 & 28.9 & 59 & 13.5 \\
\hline & Long term: $\geq 20$ to $\leq 45$ & 91 & 30.3 & 172 & 38.8 & 91 & 32.4 & 245 & 58.3 \\
\hline \multirow[t]{5}{*}{ Languages } & Sotho (predominantly Setswana) & 102 & 36.7 & 166 & 41.6 & 85 & 30.3 & 218 & 48.6 \\
\hline & $\begin{array}{l}\text { Nguni (isiZulu, isiNdebele, isiXhosa, } \\
\text { Seswati) }\end{array}$ & 54 & 24.4 & 57 & 14.7 & 45 & 16.3 & 78 & 19.6 \\
\hline & $\begin{array}{l}\text { Other local languages (Xitsonga, } \\
\text { Tshivenda) }\end{array}$ & 21 & 7.1 & 86 & 20.7 & 18 & 7.0 & 70 & 15.6 \\
\hline & Non-local African languages & 58 & 24.5 & 80 & 22.2 & 78 & 37.3 & 63 & 15.9 \\
\hline & English, Afrikaans, Portuguese & 26 & 7.4 & 3 & 0.7 & 23 & 9.1 & 1 & 0.3 \\
\hline \multirow[t]{3}{*}{ School education } & $\begin{array}{l}\text { No school or primary education } \\
\text { (Grades } 0-7 \text { ) }\end{array}$ & 26 & 6.6 & 26 & 6.6 & 22 & 10.3 & 27 & 7.2 \\
\hline & Grades 8-11 & 87 & 34.3 & 159 & 40.5 & 130 & 54.1 & 180 & 41.6 \\
\hline & Grade 12 and higher education & 148 & 54.6 & 207 & 52.9 & 97 & 35.6 & 223 & 51.2 \\
\hline
\end{tabular}

$\dagger$, Frequency; $¥$, Weighted percentage.

TABLE 2: Response percentages at baseline and end-line for selected items.

\begin{tabular}{|c|c|c|c|c|c|}
\hline Item Description & Response $\dagger$ & Group & $\begin{array}{c}\text { Baseline percentage } \\
(\%):\end{array}$ & $\begin{array}{l}\text { End-line percentage } \\
(\%) \$\end{array}$ & $\begin{array}{l}\text { Percentage point } \\
\text { difference } \S\end{array}$ \\
\hline \multirow{2}{*}{$\begin{array}{l}\text { A. Did a member of staff attend to you } \\
\text { within } 15 \text { min of arriving at the unit? }\end{array}$} & \multirow[t]{2}{*}{ Yes } & Control & 76.6 & 91.8 & 15.2 \\
\hline & & Intervention & 72.6 & 93.8 & 21.2 \\
\hline \multirow{3}{*}{$\begin{array}{l}\text { B. Did the sister ask if it was okay to } \\
\text { examine you? }\end{array}$} & \multirow[t]{3}{*}{ Yes } & Control & 56.9 & 61.0 & 4.1 \\
\hline & & Intervention & 38.1 & 64.0 & 25.9 \\
\hline & & Percentage point difference & 18.8 & -3.0 & - \\
\hline \multirow{2}{*}{$\begin{array}{l}\text { C. Did any staff member say anything } \\
\text { that upset you? }\end{array}$} & \multirow{2}{*}{ No } & Intervention & 78.1 & 91.0 & 12.9 \\
\hline & & Percentage point difference & 5.1 & -2.0 & - \\
\hline \multirow{3}{*}{$\begin{array}{l}\text { D. How did the staff speak to you } \\
\text { during labour? }\end{array}$} & \multirow[t]{3}{*}{ All staff spoke nicely } & Control & 61.5 & 81.0 & 19.5 \\
\hline & & Intervention & 47.8 & 82.6 & 34.8 \\
\hline & & Percentage point difference & 13.7 & -1.6 & - \\
\hline \multirow{2}{*}{$\begin{array}{l}\text { E. How respectfully do you think the } \\
\text { sisters treated you during your stay in } \\
\text { the labour ward? }\end{array}$} & \multirow[t]{2}{*}{ A lot of respect } & Control & 58.3 & 71.6 & 13.3 \\
\hline & & Intervention & 38.1 & 74.5 & 36.4 \\
\hline \multirow{3}{*}{$\begin{array}{l}\text { F. How satisfied were you with the } \\
\text { treatment you received in the labour } \\
\text { ward? }\end{array}$} & \multirow[t]{3}{*}{ Completely satisfied } & Control & 63.2 & 71.1 & 7.9 \\
\hline & & Intervention & 47.0 & 73.6 & 26.6 \\
\hline & & Percentage point difference & 16.2 & -2.5 & - \\
\hline
\end{tabular}

$\dagger$, Modelling of responses: Item A: Yes versus No; Item B: Yes versus No; Item C: No versus Yes; Item D: All staff spoke nicely versus Not all staff spoke nicely; Item E: A lot of respect versus Not a lot of respect; Item F: Completely satisfied versus Not completely satisfied.

$\$$ Weighted percentage.

$\S$, Percentage point difference, calculated as end-line minus baseline percentage.

T, Percentage point difference, calculated as control minus intervention group percentage.

A), the control group showed an increase of $15 \%$ in positive responses from baseline to end-line and the intervention group, an increase of $21 \%$. For both the control and intervention groups, relatively few respondents reported that remarks they perceived as upsetting had been made to them (Item C). The positive responses of the intervention units for the remaining four items started from a lower level of 14 to 20 percentage points compared to the control units.
In the end-line survey, positive responses for the intervention units 'caught up' with those of the control units, with minor differences between the two groups' responses.

Table 3 contains an extract of the main results of the weighted logistic regression with odds ratios of end-line relative to baseline and intervention group relative to control group for the six selected items. For Item A (attended 
TABLE 3: Results of weighted logistic regression with odds ratios of end-line relative to baseline and intervention relative to control group for selected items.

\begin{tabular}{|c|c|c|c|c|c|c|c|}
\hline \multirow[t]{2}{*}{ Item } & \multirow[t]{2}{*}{ Response $\dagger$} & \multicolumn{3}{|c|}{ End-line relative to baseline } & \multicolumn{3}{|c|}{ Intervention group relative to control group } \\
\hline & & Group & OR & $p *$ & Period & OR & $p *$ \\
\hline \multirow{2}{*}{$\begin{array}{l}\text { A. Did a member of staff attend to you within } \\
15 \text { min of arriving at the unit? }\end{array}$} & \multirow[t]{2}{*}{ Yes } & Control & 6.098 & $0.0007 * * *$ & Baseline & 1.204 & 0.2775 \\
\hline & & Intervention & 8.418 & $0.0001 * * *$ & End-line & 1.662 & 0.1434 \\
\hline \multirow{2}{*}{$\begin{array}{l}\text { B. Did the sister ask if it was okay to } \\
\text { examine you? }\end{array}$} & \multirow[t]{2}{*}{ Yes } & Control & 0.987 & 0.9599 & Baseline & 0.462 & $<0.0001 * * *$ \\
\hline & & Intervention & 2.381 & $0.0018^{* * *}$ & End-line & 1.114 & 0.6748 \\
\hline $\begin{array}{l}\text { C. Did any staff member say anything that } \\
\text { upset you? }\end{array}$ & No & Control & 0.904 & 0.9725 & Baseline & 0.838 & 0.7136 \\
\hline \multirow{2}{*}{$\begin{array}{l}\text { D. How did the staff speak to you during } \\
\text { labour? }\end{array}$} & \multirow[t]{2}{*}{ All staff spoke nicely } & Control & 1.801 & 0.1530 & Baseline & 0.568 & $<0.0001 * * *$ \\
\hline & & Intervention & 3.172 & $0.0009 * * *$ & End-line & 1.000 & 0.9990 \\
\hline \multirow{2}{*}{$\begin{array}{l}\text { E. How respectfully do you think the sisters } \\
\text { treated you during your stay in the labour } \\
\text { ward? }\end{array}$} & \multirow[t]{2}{*}{ A lot of respect } & Control & 1.690 & 0.1079 & Baseline & 0.443 & $<0.0001 * * *$ \\
\hline & & Intervention & 4.334 & $<0.0001 * * *$ & End-line & 1.137 & 0.3602 \\
\hline \multirow{2}{*}{$\begin{array}{l}\text { F. How satisfied were you with the treatment } \\
\text { you received in the labour ward? }\end{array}$} & \multirow[t]{2}{*}{ Completely satisfied } & Control & 1.763 & 0.0736 & Baseline & 0.525 & $<0.0001 * * *$ \\
\hline & & Intervention & 4.044 & $<0.0001 * * *$ & End-line & 1.204 & 0.1868 \\
\hline
\end{tabular}

*** Significant at $1 \%$ level.

$\dagger$, Modelling of responses: Item A: Yes versus No; Item B: Yes versus No; Item C: No versus Yes; Item D: All staff spoke nicely versus Not all staff spoke nicely; Item E: A lot of respect versus Not a lot of respect; Item F: Completely satisfied versus Not completely satisfied.

$\$$, Adjusted $p$ value $=$ Exceedance probability for accepting $\mathrm{H}_{0} \mathrm{OR}=1$ of ad hoc tests (end-line relative to baseline) and (intervention relative to control).

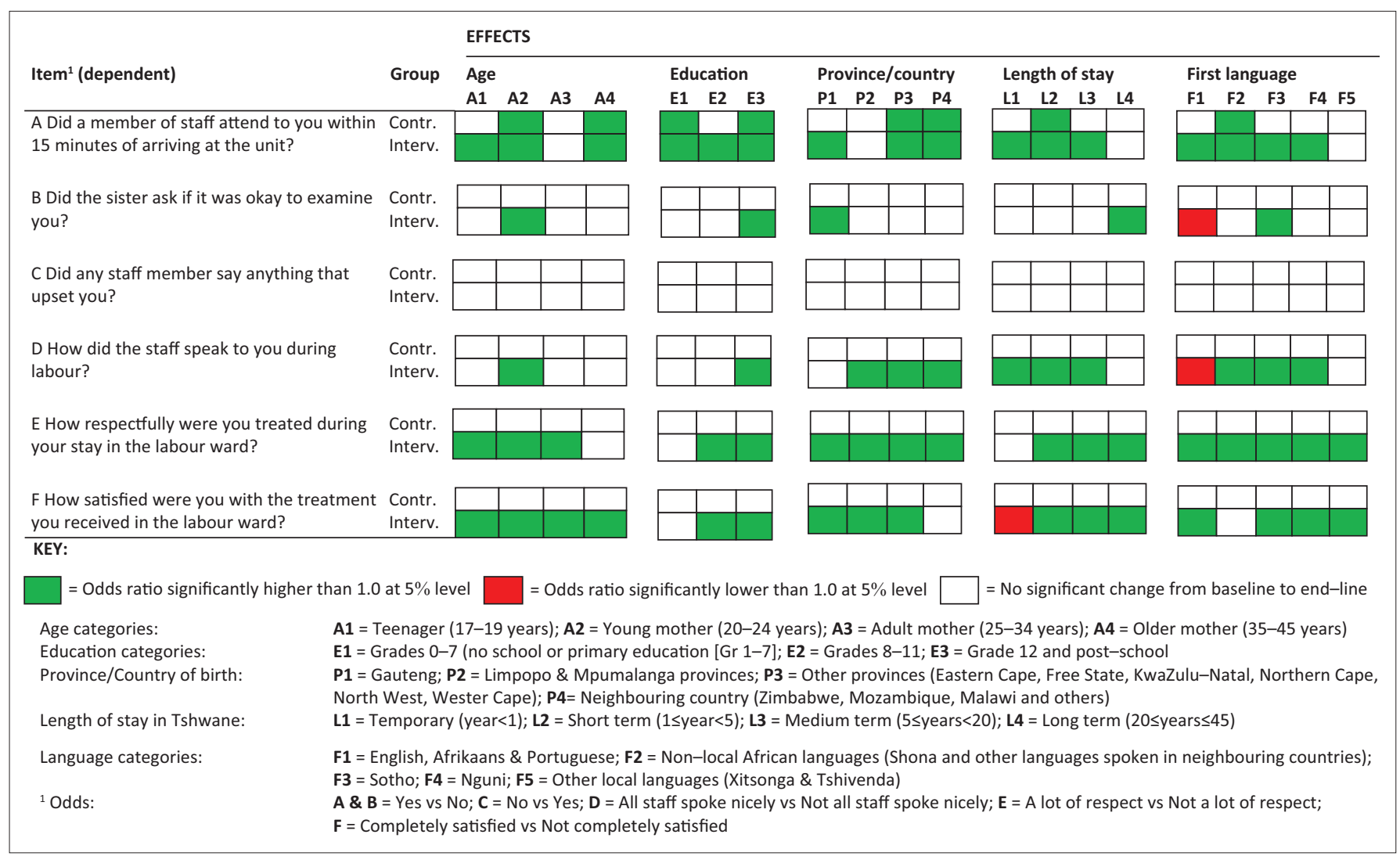

FIGURE 1: Results of weighted logistic regression modelling of cohorts comparing odds ratios of end-line versus baseline for control and intervention groups ( $n=1332$ ).

to within $15 \mathrm{~min}$ ), there was a significant positive change in women's experiences from baseline to end-line for both the control and intervention group units $(\mathrm{OR}=6.1$ and $\mathrm{OR}=8.4$; $p=0.0007$ and $p=0.0001$, respectively). There was, however, no significant change for both groups for Item $\mathrm{C}$ (staff said something upsetting). The remaining four items (B, D, E and F) showed a significant positive change from baseline to end-line regarding the intervention group units (ORs ranging between 2.4 and 4.3 , with $p$ values $\leq 0.0018$ ). There was no significant change in these items for the control group (ORs between 1.0 and 1.8; $p \geq 0.0736$ ). When comparing the intervention group with the control group, the same four items (B, D, E and F) displayed odds ratios significantly below 1 at baseline (OR from 0.4 to 0.6 ; $p<0.0001$ ). At end-line, the odds ratios for all six items (intervention group relative to control group) were above $1.0(p \geq 0.1434)$, and all were larger than the odds ratios at baseline.

Differences in odds ratios between baseline and end-line responses are visually compared for the control and intervention groups in Figure 1. The results of the weighted 
logistic regression modelling of cohorts are broken down by the sociodemographic domains of age, education, province or country of birth, length of stay in Tshwane and first language. Item A (attended to within $15 \mathrm{~min}$ ) shows odds ratios significantly higher than 1.0 from baseline to end-line for many of the categories across the different sociodemographic domains in both the control and intervention groups, with about twice as many significant domains for the intervention group. Items E (respectful treatment) and F (satisfaction) have significantly higher odds ratios for the majority of categories across the sociodemographic domains in the intervention group only. One category (length of stay in Tshwane $<1$ year) under Item $\mathrm{F}$ has an odds ratio significantly lower than 1.0 , which could possibly be explained by the low number of respondents in this category in the end-line survey (1\%). For Item D (staff spoke nicely), the higher odds ratios for the intervention group are concentrated in the domains for the province or country of birth, length of stay in Tshwane and first language. There is a significantly lower odds ratio for English, Afrikaans and Portuguese first-language speakers $(<1 \%$ of respondents in baseline and end-line surveys). Item $\mathrm{B}$ (consent to examination) has one category in each sociodemographic domain with a significantly higher odds ratio in the intervention group between baseline and endline and a lower odds ratio for English, Afrikaans and Portuguese first-language speakers. For Item C (staff made upsetting remarks), there was no significant change in any odds ratios from baseline to end-line in either the control or intervention group.

\section{Discussion}

To our knowledge, the 'working CLEVER' study ${ }^{31}$ was one of a few studies ${ }^{35,36,37,38,39,40}$ in LMICs that conducted baseline and end-line surveys to measure the change in respectful care after the implementation of an intervention to improve obstetric care. With regard to five of the six questionnaire items selected in our study as a proxy for respectful care during labour, there was a significant improvement in women's experience of childbirth in the intervention MOUs, compared with only one item in the control MOUs. Item C related to degrading communication on the part of the staff and there was no significant change in women's experience from baseline to end-line in either the control or intervention group, probably because of the high percentages of positive responses recorded at baseline, although the odds ratio was larger in the intervention group.

The first questionnaire item (A) relates to the withholding of care. The waiting time before being given attention in all units started at approximately the same service level and ended at almost the same improved level. The similarity between the before-and-after performance of the two groups may reflect the effect of the routine engagement of the district clinical specialist team on the improvement of adherence to clinical guidelines in all health facilities. Compliance with minimal patient waiting time is also addressed in different government documents, such as the 'Ideal Clinic Framework:
Definitions, Components and Checklists', ${ }^{41}$ the 'Ideal Clinical Manual' $^{\prime 2}$ and the 'National Core Standards for Health Establishments in South Africa' ${ }^{43}$ The remaining four items $(\mathrm{B}, \mathrm{D}, \mathrm{E}$ and $\mathrm{F})$ relate to obtaining consent before pelvic examinations, communication behaviour, respectful treatment and overall satisfaction with birthing care. Women delivering in the intervention-group MOUs recorded a significant improvement of $26 \%-36 \%$ in experience in these areas at the end-line versus $4 \%-20 \%$ in the control group.

Two African studies ${ }^{35,40}$ that recorded the experiences of women regarding consented care focused on other areas of consent, which does not make a valid comparison with our result possible. The Staha study was a comparative community and health-system intervention conducted to reduce disrespect and abuse in Tanzania that investigated non-consented care for surgical procedures in an intervention and a comparison between districts before and after the intervention. ${ }^{35}$ Consent to physical examinations was not included in the measurement, and there was no change in consented care practices after the intervention. The Heshima project in Kenya ${ }^{40}$ was a before-and-after intervention study that measured women's experiences of birthing care in 13 facilities using self-report and third-party observation. After the intervention, a highly significant increase was observed in consented care for pelvic examinations, namely, from $61 \%$ to $81 \%$, and women reported an increase in abandonment, although it was not statistically significant. Advocacy and influencing providers' understanding of how to provide better care could improve consented care, but this will be moderated by hurdles in the work environment. ${ }^{44}$

Communication practices in our study improved significantly after the CLEVER intervention. The Heshima study in Kenya ${ }^{40}$ recorded a non-significant decline in verbal and physical abuse but a statistically significant reduction of $7 \%$ in the proportion of women who felt humiliated or disrespected. The Staha study in Tanzania ${ }^{35}$ used language usage and friendly support during labour as care process indicators for respectful care. After the intervention, there was a highly significant improvement in the prevalence of excellent/very good language used in communications with women and the friendly support offered during labour.

In our study, respectful treatment of birthing women and complete satisfaction with treatment improved significantly in the intervention group from baseline to end-line. Tanzania's Staha project ${ }^{35}$ demonstrated a similar improvement at end-line. The authors postulated that the improvement supported the likelihood that the intervention was responsible for the reduction in disrespect and abuse. Although the Heshima study in Kenya ${ }^{40}$ demonstrated an overall decrease amongst four of their six typologies of disrespect and abuse, women's perceptions of respectful treatment or satisfaction with overall treatment during birthing were not measured. 
Another study ${ }^{37}$ reported two interventions in a large public hospital in Dar es Salaam, Tanzania - 'Open Birth Days' - to prepare women for labour and a workshop for healthcare providers to increase the knowledge of patient rights. The study did not measure specific domains of disrespect and abuse but rather the attitudes and perceptions of providers and women. With regard to women's perceptions of respect shown by providers and the quality of care received during delivery, no woman rated these as 'excellent' in the baseline assessment. After the intervention, ratings of 'excellent' for both these items increased to $22.8 \%$. The rating 'very good' for quality of care increased from $2.9 \%$ to $40.3 \%$. The number of women who reported that they were 'very satisfied' with their delivery experience improved by $66.5 \%$, from baseline $(10.0 \%)$ to follow-up $(76.5 \%)$. In our study, improvement in respect was measured on a different scale, but there was an improvement of $36.4 \%$ in the number of women who reported that they were treated 'with a lot of respect'. With regard to an improvement in the level of satisfaction experienced, there was an increase of $26.4 \%$ in the number of women who reported being 'completely satisfied' with their treatment in the end-line assessment.

Our study results indicate that midwives and managers could be engaged to mitigate disrespect and abuse, whilst flexible, adaptable teams of midwives could improve negative birth experiences. ${ }^{45}$

\section{Study's strengths and limitations}

A strength of this study is the baseline and end-line surveys on experiences of care during childbirth that were conducted at all MOUs in Tshwane district. The same survey tool was used at end-line to obtain a follow-up view of care experiences after the CLEVER intervention.

Limitations of the study relate to the fact that the MOUs in the study could not be randomised but had to be allocated purposively to minimise contamination, ${ }^{31}$ and the women participating in the two surveys consisted of convenience samples of women returning postnatally to a primary healthcare facility. Although there were differences in the demographic data categories between the two survey cohorts, this was mitigated by weighting the data to emulate the population of births. The study was also limited to a single district, and the findings may therefore not be generalisable to other areas. The validity of the data of one of the birthing sites was compromised, and the survey was repeated for that specific site.

\section{Conclusion}

CLEVER Maternity Care is a complex intervention package, and it is not always possible to link specific outcomes to specific components of the package. In addition to the demonstration of a significant reduction in perinatal morbidity and mortality, ${ }^{31}$ it appears as if the implementation of the package contributed towards a better match between women's expectations of childbirth and midwives' realities. The CLEVER package set out to change birthing mothers' experiences of care by providing the skills and tools needed to form small effective teams of midwives, adhering to highquality respectful obstetric care. The results indicate that the CLEVER package is a potential strategy to address respectful, quality obstetric care and that the integration of CLEVER Maternity Care into district health systems warrants further investigation in more healthcare facilities.

\section{Acknowledgements}

We are grateful to the healthcare professionals who participated in the intervention, the women who completed the survey and colleagues who provided input and support.

\section{Competing interests}

The authors have declared that no competing interests exist.

\section{Authors' contributions}

All authors were involved in the design of the study. S.J.O. supervised the data collection. J.G. was responsible for the statistical analysis. S.J.O. drafted the manuscript, which was reviewed and revised by A.-M.B., R.C.P. and J.G. All authors read and approved the final manuscript.

\section{Funding information}

This project was supported by the South African National Department of Health, the South African Medical Research Council Unit for Maternal and Infant Health Care Strategies and the Department of Family Medicine, University of Pretoria.

\section{Data availability statement}

Data are available on request.

\section{Disclaimer}

The views and opinions expressed in this article are those of the authors and do not necessarily reflect the official policy or position of any affiliated agency of the authors.

\section{References}

1. Larson E, Vail D, Mbaruku GM, Kimweri A, Freedman LP, Kruk ME. Moving toward patient-centered care in Africa: A discrete choice experiment of preferences for delivery care among 3003 Tanzanian women. PLoS One. 2015;10(8):e0135621. https://doi.org/10.1371/journal.pone.0135621

2. Clark K, Beatty S, Reibel T. 'What women want': Using image theory to develop expectations of maternity care framework. Midwifery. 2015;31(5):505-511. https://doi.org/10.1016/j.midw.2014.12.011

3. Sawyer A, Ayers S, Abbott J, Gyte G, Rabe H, Duley L. Measures of satisfaction with care during labour and birth: A comparative view. BMC Pregnancy Childb. 2013;13:108. https://doi.org/10.1186/1471-2393-13-108

4. World Health Organization. World Health Statistics 2018: Monitoring health for the SDGs [homepage on the Internet]. Geneva: World Health Organization; 2018 [cited 2019 Dec 3]. Available from: https://www.who.int/gho/publications/ world_health_statistics/2018/en/

5. Vogel JP, Bohren MA, Tunçalp Ö, Oladapo OT, Gülmezoglu A. Promoting respect and preventing mistreatment during childbirth. BJOG. 2015;123(5):671-674. https://doi.org/10.1111/1471-0528.13750 
6. Hollander MH, Van Hastenburg E, Van Dillen J, Van Pampus MG, De Miranda E, Stramrood CIA. Preventing traumatic childbirth experiences: 2192 women's perceptions and views. Arch Womens Ment Health. 2017;20(4):512-523. https:// doi.org/10.1007/s00737-017-0729-6

7. Lavender T. Improving quality of care during labour and childbirth and the immediate postnatal period. Best Pract Res Clin Obstet Gynaecol. 2016:36:57-67. https://doi.org/10.1016/j.bpobgyn.2016.05.011

8. Franco $L$, Marquez $L$. Effectiveness of collaborative improvement: Evidence from 27 applications in 12 less-developed and middle-income countries. BMJ Qual Saf. 2011; 20(8):658-665. https://doi.org/10.1136/bmjqs.2010.044388

9. Ten Hoope-Bender P, De Bernis L, Campbell J, et al. Improvement of maternal and newborn health through midwifery. Lancet. 2014;384(9949):1226-1235. https:// doi.org/10.1016/S0140-6736(14)60930-2

10. Ten Hoope-Bender P, Lopes S, Nove A. Midwifery 2030: A woman's pathway to health. What does this mean? Midwifery. 2016;32:1-6. https://doi.org/10.1016/j. midw.2015.10.014

11. Atun R. Health systems, systems thinking and innovation. Health Pol Plann 2012;27(Suppl 4):iv4-iv8. https://doi.org/10.1093/heapol/czs088

12. Adam T, De Savigny D. Systems thinking for strengthening health systems in LMICs: Need for paradigm shift. Health Pol Plann. 2012;27(Suppl 4):iv1-iv3. https://doi.org/10.1093/heapol/czs084

13. Oosthuizen SJ, Bergh AM, Pattinson RC. Systems thinking: A turning point for improving respectful obstetric care in South African health districts. S Afr Med J. 2018;108(11):910-914. https://doi.org/10.7196/SAMJ.2018.v108i11.13312

14. Bowser D, Hill K. Exploring evidence and abuse in facility-based childbirth: Report of a landscape analysis [homepage on the Internet]. Washington, DC: USAIDof a landscape analysis [homepage on the Internet]. Washington, DC: USAID-
TRAction Project; 2010 [cited 2017 March 18]. Available from: https://www. TRAction Project; 2010 [cited 2017 March 18]. Available from
ghdonline.orgrespectful_care_at_birth_9-20-101_final_1.pdf

15. Bohren MA, Vogel JP, Tunçalp Ö, et al. Mistreatment of women during childbirth in Abuja, Nigeria: A qualitative study on perceptions and experiences of women and health care providers. Reprod Health. 2017;14:9. https://doi.org/10.1186/ s12978-016-0265-2

16. Jewkes R, Penn-Kekana L. Mistreatment of women in childbirth: Time for action on this important dimension of violence against women. PLoS Med. 2015;12(6):e1001849. https://doi.org/10.1371/journal.pmed.1001849

17. McMahon SA, George AS, Chebet JJ, Mosha IH, Mpembeni RN, Winch PJ. Experiences of and responses to disrespectful maternity care and abuse during childbirth: A qualitative study with women and men in Morogoro Region, Tanzania. BMC Pregnancy Childb. 2014;14:268. https://doi.org/10.1186/1471-2393-14-268

18. Kruk ME, Kujawaski S, Mbaruku G, Ramsey K, Moyo W, Freedman L. Disrespectful and abusive treatment during facility delivery in Tanzania: A facility and community survey. Health Pol Plann. 2018;33(1):e26-e33. https://doi.org/10.1093/heapol/czu079

19. World Health Organization. Standards for improving quality of maternal and newborn care in health facilities [homepage on the Internet]. Geneva: World Health Organization; 2016 [cited 2017 Sep 28]. Available from: http://apps.who. int/iris/bitstream/10665/249155/1/9789241511216-eng.pdf?ua=1

20. White Ribbon Alliance. Respectful maternity care charter. Washington, DC: White Ribbon Alliance; 2011 [cited 2019 Dec 3]. Available from: https://www. whiteribbonalliance.org/wp-content/uploads/2017/11/Final_RMC_Charter.pdf

21. Tunçalp Ö, Were WM, MacLennan C, Oladapo OT, Gulmezoglu AM, Bahl R. Quality of care for pregnant women and newborns - the WHO vision. BJOG. 2015;122(8):1045-1049. https://doi.org/10.1111/1471-0528.13451

22. Bohren MA, Hunter EC, Munthe-Kaas HM, Souza JP, Vogel JP, Gülmezoglu AM Facilitators and barriers to facility based delivery in low- and middle-income countries: A qualitative evidence synthesis. Reprod Health. 2014;11(1):71. https://doi.org/10.1186/1742-4755-11-71

23. Bradley S, Kamwendo F, Chipeta E, Chimwaza W, De Pinho H, McAuliffe E. Too few staff, too many patients: A qualitative study of the impact on obstetric care providers and on quality of care in Malawi. BMC Pregnancy Childb. 2015;15:65. https://doi.org/10.1186/s12884-015-0492-5

24. Byford-Richardson L, Walker M, Muckle W, et al. Barriers to access of maternity care in Kenya: A social perspective. J Obstet Gynaecol Can. 2013;35(2):125-130. https://doi.org/10.1016/S1701-2163(15)31016-1

25. Gashaye KT, Tsegaye AT, Shiferaw G, Worku AG, Abebe SM. Client satisfaction with existing labor and delivery care and associated factors among mothers who gave birth in University of Gondar Teaching Hospital, Northwest Ethiopia: Institution based cross sectional study. PLoS One. 2019;14(2);e0210693. https://doi. org/10.1371/journal.pone.0210693
26. Mcconville F, Lavender T. Quality of care and midwifery services to meet the needs of women and newborns. BJOG. 2014;121(Suppl. 4):8-10. https://doi. of women and newborns.
org/10.1111/1471-0528.12799

27. World Health Organization. Everybody's business: Strengthening health systems to improve health outcomes: WHO's framework for action [homepage on the Internet]. Geneva: World Health Organization; 2007 [cited 2018 Mar 23]. Available from: apps.who.int/iris/bitstream/10665/43918/1/9789241596077_eng.pdf

28. Chadwick RJ, Cooper D, Harries J. Narratives of distress about birth in South African public maternity settings: A qualitative study. Midwifery. 2014;30(7): 862-868. https://doi.org/10.1016/j.midw.2013.12.014

29. Moyer CA, Adongo PB, Aborigo RA, Hodgson A, Engmann CM. 'They treat you like you are not a human being': Maltreatment during labour and delivery in rural northern Ghana. Midwifery. 2014;30(2):262-268. https://doi.org/10.1016/ j.midw.2013.05.006

30. Bohren MA, Vogel JP, Hunter EC, et al. The mistreatment of women during childbirth in health facilities globally: A mixed-methods systematic review. PLoS Med. 2015;12(6):e1001847. https://doi.org/10.1371/journal.pmed.1001847

31. Oosthuizen SJ, Bergh A-M, Grimbeek J, Pattinson RC. Midwife-led obstetric units working 'CLEVER': Improving perinatal outcome indicators in a South African health district. S Afr Med J. 2019;109(2):95-101. https://doi.org/10.7196/ SAMJ.2019.v109i2.13429

32. Oosthuizen SJ, Bergh A-M, Pattinson RC, Grimbeek J. It does matter where you come from: Mothers' experiences of childbirth in midwife obstetric units, Tshwane, South Africa. Reprod Health. 2017;14:151. https://doi.org/10.1186/ s12978-017-0411-5

33. SAS Institute, Inc. SAS 9.4 In-database products: User's guide. 6th edn. Cary, NC: SAS Institute, Inc.; 2015.

34. Lohr SL. Sampling: Design and analysis. 2nd ed. Boston, MA: Brooks/Cole, 2010; pp. 348-349.

35. Kujawaski S, Freedman L, Ramsey K, et al. Community and health system intervention to reduce disrespect and abuse during childbirth in Tanga region, Tanzania: A comparative before-and-after study. PLoS Med. 2017;14(7):e1002341. https://doi.org/10.1371/journal.pmed.1002341

36. Ndwiga C, Warren C, Ritter J, Sripad P, Abuya T. Exploring provider perspectives on respectful maternity care in Kenya: 'Work with what you have'. Reprod Health 2017;14(1):99. https://doi.org/10.1186/s12978-017-0364-8

37. Ratcliffe $H$, Sando D, Lyatuu G, et al. Mitigating disrespect and abuse during childbirth in Tanzania: An exploratory study of the effects of two facility-based interventions in a large public hospital. Reprod Health. 2016;13:79. https://doi. org/10.1186/s12978-016-0187-z

38. Kambala C, Lohmann J, Mazalale J, et al. Perceptions of quality across the maternal care continuum in the context of a health financing intervention: Evidence from a mixed methods study in rural Malawi. BMC Health Serv Res. 2017;17:392. https:// doi.org/10.1186/s12913-017-2329-6

39. Sheferaw ED, Bazant E, Gibson H, et al. Respectful maternity care in Ethiopian public health facilities. Reprod Health. 2017:14:60. https://doi.org/10.1186/ s12978-017-0323-4

40. Abuya T, Ndwiga C, Ritter J, et al. The effect of a multi-component intervention on disrespect and abuse during childbirth in Kenya. BMC Pregnancy Childb. 2015;15:e224. https://doi.org/10.1186/s12884-015-0645-6

41. Republic of South Africa, Department of Health. Final ideal clinic frameworkversion 19 (July 2020): Ideal clinic ${ }^{\mathrm{TM}}$ definitions, components and checklists [homepage on the Internet]. Tshwane: National Department of Health; 2020 [cited 2020 Aug 1]. Available from: https://www.idealhealthfacility.org.za/

42. Republic of South Africa, Department of Health. Final ideal clinic manual - version 19 (July 2020) [homepage on the Internet]. Pretoria: National Department of Health; 2020 [cited 2019 Dec 3]. Available from: https://www.idealhealthfacility.org.za/

43. Republic of South Africa, Department of Health. National core standards for health establishments in South Africa: Towards quality care for patients [homepage on the Internet]. Tshwane: National Department of Health; 2011 [cited 2018 July 13]. Available from: http://www.rhap.org.za/wp-content/uploads/2014/05/NationalCore-Standards-2011-1.pdf

44. Sharma G, Mathai M, Dickson KE, et al. Quality care during labour and birth: A multicountry analysis of health system bottlenecks and potential solutions. BMC Pregnancy Childb. 2015;15(Suppl 2):S2. https://doi.org/10.1186/1471-2393-15-S2-S2

45. Cornthwaite K, Edwards S, Siassakos D. Reducing risk in maternity by optimising teamwork and leadership: An evidence-based approach to save mothers and babies. Best Pract Res Clin Obstet Gynaecol. 2013;27(4):571-581. https://doi. org/10.1016/j.bpobgyn.2013.04.004 